\title{
Biometry of Adrenal Glands of Mixed-Breed Dogs
}

\author{
Leonardo Oliveira Trivilin', Francisco de Assis Pessoa Júnior', Maria Aparecida da Silva', \\ Leandro André Milholli', Felipe Martins Pastor', Adriano Lima Stelzer Bindaco', \\ Sebastião Martins Filho² \& Louisiane de Carvalho Nunes ${ }^{1}$
}

\begin{abstract}
Background: Differences of the size of the adrenal glands, in healthy dogs or in endocrinopathies, undermine correct diagnosis of endocrine disorders and evaluations of the adrenal cortex in relation to its size and possible correlation with endocrinopathies are rare. The aim of the present study was to perform measurements of the length, width, thickness and weight of the adrenal glands of young, adult and elderly mixed-breed dogs and correlate them with the age, sex and weight of animals. In addition, the areas occupied by the zona glomerulosa, zona fasciculata, and zona reticularis of the adrenal cortex were measured in order to establish a microscopic biometric pattern.

Material, Methods \& Results: The right and left adrenal glands of 12 young (six females and six males), 12 adults (six females and six males), and 12 elderly (six females and six males), all mongrels, derived from routine and necropsied in the Animal Pathology Sector of the Veterinary Hospital of the Federal University of Espírito Santo (HOVET-UFES) were weighed and the length, width, and thickness were measured. For the microscopic measurement of the adrenal cortex, 10 randomly selected samples were submitted to routine histological processing and the microscope slides were observed under a light microscope at $5 \times$ and $10 \times$ objectives, photodocumented and measurements were obtained from a random portion of the adrenal cortex and the zones composing the cortex were measured in triplicate with the aid of the computerized image analysis software. The left adrenal showed a greater average length than the right adrenal in young, adult, and elderly dogs. The size of the glands in the young and adult dogs is not influenced by the sex of the animals, but in older dogs the females had a greater mean width than the males. The weight of the animals presented a positive correlation in relation to the length and weight of the right and left adrenal glands in all studied groups. The age did not influence the length and weight variables of the glands. However, some differences in thickness and width were observed in the elderly group compared to those in other groups. For the microscopic measurements in the right adrenal gland, the cortex was $1.53 \mathrm{~mm}$, being $0.21 \mathrm{~mm}$ for the glomerular zone (14.6\% of the total adrenal cortex), $1.04 \mathrm{~mm}$ for the zona fasciculata (66.9\%), and $0.29 \mathrm{~mm}$ for the zona reticularis (18.5\%). In the left adrenal gland, the cortex was $1.83 \mathrm{~mm}$, being $0.23 \mathrm{~mm}$ for the glomerular zone (13.2\% of the total adrenal cortex), $1.23 \mathrm{~mm}$ for the zona fasciculata $(63.96 \%)$, and 0.37 for the zona reticularis $(22.84 \%)$.

Discussion: Studies on the size of the adrenal gland in dogs using macroscopic biometrics are scarce, and the current study presents results regarding mixed-breed (male and female) dogs of different ages, which presented variation in size and weight, which could also influence the size of the adrenal gland. Thus, it can be observed that a variation of measurements can be found, especially for dogs with no defined breed. These results demonstrate the importance of studies that perform the macroscopic analysis of such glands. It was concluded that there was a clear variation in the size of the adrenal glands in mixed-breed dogs of different ages and both sexes; the left adrenal showed greater lengths and weights than the right gland. The sex of the animals did not influence the size of the glands in young and adult dogs, but in elderly dogs, the females showed a greater mean width than the males. The right and left adrenal cortices are formed at a greater percentage by the zona fasciculata, followed by the zona reticularis and zona glomerulosa.
\end{abstract}

Keywords: canine, measurement, adrenal glands.

DOI: $10.22456 / 1679-9216.102249$

${ }^{1}$ Programa de Pós-Graduação em Ciências Veterinárias, Centro de Ciências Agrárias e Engenharias (CCAE), Universidade Federal do Espírito Santo (UFES), ES, Brazil. ${ }^{2}$ Departamento de Estatística, Universidade Federal de Viçosa (UFV), MG, Brazil. CORRESPONDENCE: L.O. Trivilin [leotrivilin@ gmail.com]. Departamento de Medicina Veterinária, CCAE - UFES. Alto Universitário s/nº. CEP 29500-000 Alegre, ES, Brazil. 


\section{INTRODUCTION}

The adrenal glands of dogs measure about 20$30 \mathrm{~mm}$ in length, $10 \mathrm{~mm}$ in width, and $5 \mathrm{~mm}$ in height $[1,25]$. However, was reported that adrenal size is difficult to determine since it appears to be influenced by several factors; for a mean-size dog, the glands measure about $25 \times 10 \times 5 \mathrm{~mm}$ [8]. Nevertheless, several authors have reported measuring the glands by means of ultrasound examinations in healthy animals, or even in the diagnosis of diseases affecting the adrenal glands, finding values that diverge from each other $[2,6,10,12,15,19]$.

The sonographic error could vary from $0 \%$ for the measurement of the length of the right adrenal gland to $25.21 \%$ for the thickness of the left cranial pole. These authors also observed that ultrasound measurements underestimated the actual adrenal size. These differences in the determination of the size of the adrenal glands, whether in healthy dogs or in animals with endocrinopathies, often undermine the correct diagnosis of endocrine disorders [20].

In view of the above, the objective was to establish macroscopic measures of length, width, and thickness, as well as to determine the weight of adrenal glands of young, adult, and elderly mixed-breed dogs, and correlate them with the age, sex and weight of the animals. In addition to measuring the areas occupied by the zona glomerulosa, zona fasciculata, and zona reticularis of the adrenal cortex in order to establish a microscopic biometric pattern, as well as to obtain morphological parameters that can be used in the study of adrenal diseases and facilitation of diagnoses, whether clinical or ultrasonographic.

\section{MATERIALS AND METHODS}

\section{Animals}

In order to carry out the study, 36 dogs were used, 12 young ( 6 females and 6 males), 12 adults ( 6 females and 6 males), and 12 elderlies ( 6 females and 6 males), all mongrels, derived from routine and necropsied in the Setor de Patologia Animal of the Hospital Veterinário of the Universidade Federal do Espírito Santo (HOVET-UFES). The experiment was developed following the ethical precepts of animal experimentation.

The animals were sexed, weighed, and had their age estimated by their dental arches: young animals have deciduous teeth and premolars but not molars, adults have premolars and molars but not deciduous teeth, older animals have dental wear or are even missing teeth [17].

\section{Necropsy and sampling}

Necropsy was performed according to the technique established by the Setor de Patologia Animal (HOVET-UFES), with the main alterations being observed and the right and left adrenal glands collected. The glands were accessed and identified in the medial cranial pole of the corresponding kidney.

Initially, the adrenal glands were dissected, weighed on a precision scale, and the length, width (cranial pole and caudal), and thickness were measured using a digital caliper. To perform the microscopic biometry of the adrenal cortex, the right and left adrenal glands were randomly selected from 10 animals (different ages and sexes, without any diseases related to the adrenal gland) and fixed in $10 \%$ formalin solution.

\section{Histopathology analysis}

The glands were sectioned longitudinally and submitted to routine histological processing for inclusion in paraffin and section of $5 \mu \mathrm{m}$ was subjected to hematoxylin and eosin (H\&E) staining.

The microscope slides were observed under a light microscope at $5 \times$ and $10 \times$ objectives and photodocumented for posterior measurement of the cortex and its zones with the aid of the computerized image analysis software DinoCapture 2.0 ${ }^{1}$.

Measurements were obtained from a photomicroscopic image, where a random portion of the adrenal cortex and the zones composing the cortex were measured in triplicate. Measurements were obtained from the right and left adrenal glands of each animal.

The measurement of the zona glomerulosa was based on the histological characteristics [16]. The measurements of the zona fasciculata and the zona reticularis were based on the histological characteristics [11].

\section{Statistics analysis}

For the statistical analysis of this study, nonparametric tests were used. The Wilcoxon-MannWhitney test $(\alpha=5 \%)$ evaluated the influence of the sex of the animal on adrenal size within each group separately. The influence of weight on gland size was studied using Spearman's correlation $(\alpha=5 \%)$. The 
influence of animal sex on gland size was determined using the Kruskal-Wallis test followed by Dunn's posthoc test $(\alpha=5 \%)$. For the microscopic measurement, the coefficient of variation $(\mathrm{CV} \%)$ and the percentage of occupation of the histological zones of the adrenal cortex were obtained. Furthermore, the Kruskal-Wallis test followed by Dunn's post-hoc test $(\alpha=5 \%)$ was used to evaluate the histological zones of the adrenal gland cortex. The difference between the histological areas of the right and the left gland was evaluated using the Wilcoxon-Mann-Whitney test $(\alpha=5 \%)$.

\section{RESULTS}

The average length of the right adrenal gland was $19.92 \mathrm{~mm}$ in young dogs, while the left adrenal gland showed an average length of $21.67 \mathrm{~mm}$. The average width of the cranial pole of the right adrenal was $12.08 \mathrm{~mm}$, while that of the left was $11.92 \mathrm{~mm}$. For the average width of the caudal pole, the right adrenal gland presented $5.67 \mathrm{~mm}$, while that of the left was $5.92 \mathrm{~mm}$. The average thickness of the right adrenal gland was $4.91 \mathrm{~mm}$ and that of the left was $4.58 \mathrm{~mm}$. The average weight of the right gland was $0.61 \mathrm{~g}$ and that of the left was $0.75 \mathrm{~g}$ (Table 1).

In adult dogs, the right adrenal gland had an average length $21.92 \mathrm{~mm}$, mean cranial pole and caudal pole widths of $12.92 \mathrm{~mm}$ and $8.08 \mathrm{~mm}$, respectively, average thickness of $5.25 \mathrm{~mm}$, and mean weight of 0.84 g. The left adrenal gland had an average length of 23.83 $\mathrm{mm}$, average cranial pole and caudal pole widths of 13 $\mathrm{mm}$ and $8 \mathrm{~mm}$, respectively, average thickness of 5.35 $\mathrm{mm}$, and mean weight of $0.89 \mathrm{~g}$ (Table 2).

In the group of older dogs, the average length of the right adrenal was $22.33 \mathrm{~mm}$ and that of the left gland was $25.42 \mathrm{~mm}$. The average width of the cranial pole of the right adrenal was $13.92 \mathrm{~mm}$ and that of the left adrenal was $12.42 \mathrm{~mm}$. The average width of the caudal pole to the right adrenal gland was $6.75 \mathrm{~mm}$ and that of the left adrenal was $7.17 \mathrm{~mm}$. The average thicknesses of the left and right adrenal glands were both $6.08 \mathrm{~mm}$. The average right adrenal weight was $1.05 \mathrm{~g}$ and the left adrenal weight was $1.22 \mathrm{~g}$ (Table 3 ).

The influence of the sex of the animals on the size of the glands was also evaluated and no significant difference was found in young (Table 4) and adult (Table 5) dogs. However, in the group of elderly dogs, females were significantly different from males in that they showed a greater average caudal pole width of the right adrenal and width of the cranial pole of the left adrenal (Table 6).

It was also evaluated whether the weight of the animals influenced the size of the gland (Table 7). The results obtained for the young dogs showed a significant positive correlation with the right adrenal length $(\mathrm{r}=0.63, P<0.05)$ and weight $(\mathrm{r}=0.73, P<$ $0.05)$. For the left adrenal, there was a significant correlation between the gland weight and animal weight, with a correlation of $0.84(P<0.05)$. In the adult dogs, the correlations between the weight of the animals and the length (0.69), caudal pole width (0.76), and weight $(0.82)$ of the right gland were significant $(P<0.05)$.

The correlation between the animal weight and left adrenal length and weight was significant, with values of 0.81 and $0.61(P<0.05)$, respectively. For the elderly dogs, there was significant correlation between the animal weight and all tested right adrenal variables. For the left adrenal, significance was only not observed in the caudal pole width.

The influence of age on the size (length, width, and thickness) and weight of the right and left adrenal glands was evaluated. The results demonstrated that adult animals have a significantly higher mean caudal pole width in the right adrenal than do young and elderly animals. In addition, older animals have a significantly thicker left adrenal gland than do young and adult animals (Table 8).

The influence of the sex of the animals on the length, width, thickness, and weight of the adrenal gland was evaluated. The results showed that elderly females, on average, have a thicker right adrenal gland than young females, but did not differ from adult females (Table 9). For males, the analyses revealed that elderly dogs differ from adult and young dogs in relation to the width of the caudal pole in the right adrenal, a difference also observed for the width of the cranial pole in the left adrenal (Table 10).

\section{Microscopic measurement of the adrenal cortex and its} zones

The right adrenal cortex measured $1.53 \mathrm{~mm}$ : $0.21 \mathrm{~mm}$ for the zona glomerulosa, $1.04 \mathrm{~mm}$ for the zona fasciculata, and $0.29 \mathrm{~mm}$ for the zona reticularis. In the left adrenal gland, the cortex measured 1.83 $\mathrm{mm}$ : the zona glomerulosa zone comprised $0.23 \mathrm{~mm}$, the zona fasciculata $1.23 \mathrm{~mm}$, and the zona reticularis $0.37 \mathrm{~mm}$. The mean measurements of the right and left 
adrenal glands, as well as their histological zonings, are shown in Figure 1.

The results obtained for each histological zone in the cortex of the right adrenal gland and arranged as the percentage of occupancy were $14.6 \%$ for the zona glomerulosa, $66.9 \%$ for the zona fasciculata, and $18.5 \%$ for the zona reticularis. For the histological zones of the left adrenal cortex, $13.2 \%$ was the zona glomerulosa, $63.96 \%$ was the zona fasciculata, and $22.84 \%$ was the zona reticularis.
Within the context of variation in the measurement of the adrenal gland, either macroscopically or microscopically, it was observed that in the right adrenal gland, the zone that presents the most variation in size is the zona reticularis (CV 45.59\%), followed by the zona glomerulosa (CV 30.15\%) and finally the zona fasciculata (CV 25.56\%). In the left adrenal gland, the zona reticularis also showed the greatest variation (CV 51.48\%), followed by the zona fasciculata (CV $51.38 \%$ ) and zona glomerulosa (CV 31.92\%).

Table 1. Body weight, sex, length, width, thickness, and weight of the right and left adrenals of young dogs ${ }^{*}$ necropsied in the Setor de Patologia Animal of the Hospital Veterinário of the Universidade Federal do Espírito Santo (HOVET-UFES).

\begin{tabular}{|c|c|c|c|c|c|c|c|c|c|c|c|c|}
\hline \multirow{3}{*}{ ID } & \multirow{3}{*}{ Weight } & \multirow{3}{*}{ Sex } & \multicolumn{5}{|c|}{ Right adrenal gland } & \multicolumn{5}{|c|}{ Left adrenal gland } \\
\hline & & & \multirow{2}{*}{$\mathrm{L}$} & \multicolumn{2}{|c|}{ Wi } & \multirow{2}{*}{$\mathrm{T}$} & \multirow{2}{*}{ We } & \multirow{2}{*}{$\mathrm{L}$} & \multicolumn{2}{|c|}{ Wi } & \multirow{2}{*}{$\mathrm{T}$} & \multirow{2}{*}{ We } \\
\hline & & & & cranial & caudal & & & & cranial & caudal & & \\
\hline AN03 & 9 & $\mathrm{~F}$ & 20 & 12 & 5 & 3.5 & 0.4 & 22 & 12 & 5 & 4 & 0.46 \\
\hline AN16 & 11 & $\mathrm{~F}$ & 22 & 16 & 6 & 5 & 0.83 & 23 & 11 & 7 & 5 & 0.81 \\
\hline AN32 & 14 & $\mathrm{~F}$ & 28 & 11 & 7 & 6 & 0.90 & 30 & 12 & 6 & 6 & 0.96 \\
\hline AN34 & 6 & $\mathrm{~F}$ & 17 & 8 & 6 & 4 & 0.35 & 21 & 13 & 3 & 4 & 0.42 \\
\hline AN35 & 8 & $\mathrm{~F}$ & 22 & 10 & 6 & 5 & 0.61 & 23 & 10 & 8 & 5 & 0.66 \\
\hline AN36 & 12 & $\mathrm{~F}$ & 24 & 19 & 5 & 5 & 0.82 & 25 & 14 & 8 & 4 & 0.89 \\
\hline AN13 & 13 & $\mathrm{M}$ & 18 & 12 & 5 & 4 & 0.5 & 19 & 12 & 5 & 4 & 1.7 \\
\hline AN28 & 9 & M & 21 & 16 & 6 & 5 & 0.81 & 24 & 12 & 7 & 5 & 0.84 \\
\hline AN29 & 12 & M & 18 & 10 & 7 & 6 & 0.66 & 20 & 15 & 5 & 5 & 0.70 \\
\hline AN30 & 2 & M & 12 & 10 & 5 & 5 & 0.30 & 13 & 10 & 4 & 5 & 0.36 \\
\hline AN31 & 10 & M & 24 & 12 & 6 & 6 & 0.89 & 26 & 15 & 9 & 5 & 1.0 \\
\hline AN33 & 2 & M & 13 & 9 & 4 & 3 & 0.21 & 14 & 7 & 4 & 3 & 0.22 \\
\hline
\end{tabular}

ID: identification; L: length (mm); Wi: width (mm); T: thickness (mm); We: weight of the gland (g). *Identification according to the dental arch.

Table 2. Body weight, sex, length, width, thickness, and weight of the right and left adrenals of adult dogs* necropsied in the Setor de Patologia Animal of the Hospital Veterinário of the Universidade Federal do Espírito Santo (HOVET-UFES).

\begin{tabular}{|c|c|c|c|c|c|c|c|c|c|c|c|c|}
\hline \multirow{3}{*}{ ID } & \multirow{3}{*}{ Weight } & \multirow{3}{*}{ Sex } & \multicolumn{5}{|c|}{ Right adrenal gland } & \multicolumn{5}{|c|}{ Left adrenal gland } \\
\hline & & & \multirow{2}{*}{$\mathrm{L}$} & \multicolumn{2}{|c|}{ Wi } & \multirow{2}{*}{$\mathrm{T}$} & \multirow{2}{*}{ We } & \multirow{2}{*}{$\mathrm{L}$} & \multicolumn{2}{|c|}{ Wi } & \multirow{2}{*}{$\mathrm{T}$} & \multirow{2}{*}{ We } \\
\hline & & & & cranial & caudal & & & & cranial & caudal & & \\
\hline AN04 & 16 & $\mathrm{~F}$ & 25 & 13 & 9 & 4 & 1 & 28 & 10 & 8 & 5 & 0.97 \\
\hline AN09 & 15,3 & $\mathrm{~F}$ & 19 & 12 & 12 & 5 & 0.74 & 21 & 13 & 7 & 7 & 0.88 \\
\hline AN17 & 12,0 & $\mathrm{~F}$ & 25 & 17 & 10 & 6 & 1.14 & 28 & 20 & 5 & 7 & 1.16 \\
\hline AN18 & 11,0 & $\mathrm{~F}$ & 20 & 14 & 6 & 5 & 0.71 & 20 & 9 & 7 & 5 & 0.83 \\
\hline AN20 & 12,0 & $\mathrm{~F}$ & 18 & 17 & 7 & 6 & 0.80 & 22 & 11 & 8 & 5 & 1.08 \\
\hline AN22 & 10,0 & $\mathrm{~F}$ & 18 & 12 & 6 & 4 & 0.53 & 20 & 9 & 7 & 4 & 0.47 \\
\hline AN01 & 9 & M & 20 & 9 & 6 & 4 & 0.5 & 21 & 13 & 5 & 4.5 & 0.56 \\
\hline AN02 & 6,6 & M & 19 & 9 & 6 & 4.5 & 0.45 & 20 & 10 & 6 & 4.5 & 0.5 \\
\hline AN06 & 24,5 & M & 30 & 18 & 12 & 5 & 1.63 & 32 & 23 & 13 & 5 & 1.8 \\
\hline AN07 & 15,5 & M & 24 & 11 & 9 & 6.3 & 1 & 25 & 14 & 6 & 6 & 1 \\
\hline AN08 & 17,7 & M & 25 & 10 & 7 & 6.2 & 0.82 & 28 & 12 & 7 & 5.2 & 0.77 \\
\hline AN10 & 13,8 & M & 20 & 13 & 7 & 7 & 0.73 & 21 & 12 & 8 & 6 & 0.71 \\
\hline
\end{tabular}

ID: identification; L: length (mm); Wi: width (mm); T: thickness (mm); We: weight of the gland (g). *Identification according to the dental arch. 
Table 3. Body weight, sex, length, width, thickness, and weight of the right and left adrenals of elderly dogs* necropsied in the Setor de Patologia Animal of the Hospital Veterinário of the Universidade Federal do Espírito Santo (HOVET-UFES).

\begin{tabular}{|c|c|c|c|c|c|c|c|c|c|c|c|c|}
\hline \multirow{3}{*}{ ID } & \multirow{3}{*}{ Weight } & \multirow{3}{*}{ Sex } & \multicolumn{5}{|c|}{ Right adrenal gland } & \multicolumn{5}{|c|}{ Left adrenal gland } \\
\hline & & & \multirow{2}{*}{$\mathrm{L}$} & \multicolumn{2}{|c|}{$\mathrm{Wi}$} & \multirow{2}{*}{$\mathrm{T}$} & \multirow{2}{*}{ We } & \multirow{2}{*}{$\mathrm{L}$} & \multicolumn{2}{|c|}{$\mathrm{Wi}$} & \multirow{2}{*}{$\mathrm{T}$} & \multirow{2}{*}{ We } \\
\hline & & & & cranial & caudal & & & & cranial & caudal & & \\
\hline AN05 & 30 & $\mathrm{~F}$ & 36 & 16 & 12 & 11 & 2.82 & 40 & 17 & 10 & 11 & 3.32 \\
\hline AN12 & 30 & $\mathrm{~F}$ & 25 & 16 & 6 & 7 & 1.48 & 28 & 15 & 5 & 8 & 1.61 \\
\hline AN14 & 31 & $\mathrm{~F}$ & 28 & 16 & 10 & 6 & 1.66 & 29 & 12 & 10 & 6 & 1.60 \\
\hline AN21 & 11 & $\mathrm{~F}$ & 20 & 14 & 6 & 5 & 0.80 & 22 & 11 & 7 & 5 & 0.70 \\
\hline AN24 & 13 & $\mathrm{~F}$ & 17 & 10 & 7 & 6 & 0.48 & 21 & 15 & 6 & 4 & 0.65 \\
\hline AN27 & 19 & $\mathrm{~F}$ & 21 & 11 & 7 & 7 & 1.03 & 27 & 12 & 7 & 6 & 1.34 \\
\hline AN11 & 11 & $\mathrm{M}$ & 18 & 8 & 5 & 5 & 0.41 & 19 & 10 & 5 & 4 & 0.34 \\
\hline AN15 & 16 & $\mathrm{M}$ & 22 & 15 & 5 & 5 & 0.70 & 22 & 11 & 7 & 6 & 0.87 \\
\hline AN19 & 6 & M & 11 & 10 & 4 & 3 & 0.21 & 23 & 10 & 8 & 6 & 0.92 \\
\hline AN23 & 14 & $\mathrm{M}$ & 19 & 14 & 6 & 5 & 0.70 & 20 & 11 & 7 & 6 & 0.80 \\
\hline AN25 & 21 & M & 26 & 19 & 6 & 8 & 1.41 & 28 & 14 & 7 & 6 & 1.52 \\
\hline AN26 & 18 & M & 25 & 18 & 7 & 5 & 0.90 & 26 & 11 & 7 & 5 & 1.00 \\
\hline
\end{tabular}

ID: identification; L: length (mm); Wi: width (mm); T: thickness (mm); We: weight of the gland (g). *Identification according to the dental arch.

Table 4. Comparison between the average length, width, thickness, and weight of the right and left adrenals of young mongrel dogs necropsied in the Setor de Patologia Animal of the Hospital Veterinário of the Universidade Federal do Espírito Santo (HOVET-UFES), in relation to the sex of the animal (males and females).

\begin{tabular}{|c|c|c|c|c|c|c|c|c|c|c|}
\hline \multirow{3}{*}{ Sex } & \multicolumn{5}{|c|}{ Right adrenal gland } & \multicolumn{5}{|c|}{ Left adrenal gland } \\
\hline & \multirow{2}{*}{$\mathrm{L}$} & \multicolumn{2}{|c|}{ Wi } & \multirow{2}{*}{$\mathrm{T}$} & \multirow{2}{*}{ We } & \multirow{2}{*}{$\mathrm{L}$} & \multicolumn{2}{|c|}{ Wi } & \multirow{2}{*}{$\mathrm{T}$} & \multirow{2}{*}{ We } \\
\hline & & cranial & Caudal & & & & cranial & caudal & & \\
\hline Female & $22.17 \mathrm{a}$ & $12.67 \mathrm{a}$ & $5.83 \mathrm{a}$ & $4.75 \mathrm{a}$ & $0.65 \mathrm{a}$ & $24.00 \mathrm{a}$ & $12.00 \mathrm{a}$ & $6.17 \mathrm{a}$ & $4.67 \mathrm{a}$ & $0.70 \mathrm{a}$ \\
\hline Male & $17.67 \mathrm{a}$ & $11.50 \mathrm{a}$ & $5.50 \mathrm{a}$ & $4.83 \mathrm{a}$ & $0.56 \mathrm{a}$ & $19.33 \mathrm{a}$ & $11.83 \mathrm{a}$ & $5.67 \mathrm{a}$ & $4.50 \mathrm{a}$ & $0.80 \mathrm{a}$ \\
\hline
\end{tabular}

L: length (mm); Wi: width (mm); T: thickness (mm); We: weight of the gland (g). *Identification according to the dental arch. Averages followed by the same letter in the column do not differ from each other by the Wilcoxon-Mann-Whitney test (considering $\alpha=5 \%$ ).

Table 5. Comparison between the average length, width, thickness, and weight of the right and left adrenals of adult mongrel dogs necropsied in the Setor de Patologia Animal of the Hospital Veterinário of the Universidade Federal do Espírito Santo (HOVET-UFES), in relation to the sex of the animal (males and females).

\begin{tabular}{|c|c|c|c|c|c|c|c|c|c|c|}
\hline \multirow{3}{*}{ Sex } & \multicolumn{5}{|c|}{ Right adrenal gland } & \multicolumn{5}{|c|}{ Left adrenal gland } \\
\hline & \multirow{2}{*}{$\mathrm{L}$} & \multicolumn{2}{|c|}{ Wi } & \multirow{2}{*}{$\mathrm{T}$} & \multirow{2}{*}{ We } & \multirow{2}{*}{$\mathrm{L}$} & \multicolumn{2}{|c|}{ Wi } & \multirow{2}{*}{$\mathrm{T}$} & \multirow{2}{*}{ We } \\
\hline & & cranial & caudal & & & & cranial & caudal & & \\
\hline Female & $20.83 a$ & $14.17 \mathrm{a}$ & $8.33 \mathrm{a}$ & $5.00 \mathrm{a}$ & $0.82 \mathrm{a}$ & $23.17 \mathrm{a}$ & $12.00 \mathrm{a}$ & $7.00 \mathrm{a}$ & $5.50 \mathrm{a}$ & $0.90 \mathrm{a}$ \\
\hline Male & $23.00 \mathrm{a}$ & $11.67 \mathrm{a}$ & $7.83 \mathrm{a}$ & $5.50 \mathrm{a}$ & $0.86 \mathrm{a}$ & $24.50 \mathrm{a}$ & $14.00 \mathrm{a}$ & $7.50 \mathrm{a}$ & $5.20 \mathrm{a}$ & $0.89 \mathrm{a}$ \\
\hline
\end{tabular}

L: length (mm); Wi: width (mm); T: thickness (mm); We: weight of the gland (g). *Identification according to the dental arch. Averages followed by the same letter in the column do not differ from each other by the Wilcoxon-Mann-Whitney test (considering $\alpha=5 \%$ ).

Table 6. Comparison between the average length, width, thickness, and weight of the right and left adrenals of elderly mongrel dogs necropsied in the Setor de Patologia Animal of the Hospital Veterinário of the Universidade Federal do Espírito Santo (HOVET-UFES), in relation to the sex of the animal (males and females).

\begin{tabular}{|c|c|c|c|c|c|c|c|c|c|c|}
\hline \multirow{3}{*}{ Sex } & \multicolumn{5}{|c|}{ Right adrenal gland } & \multicolumn{5}{|c|}{ Left adrenal gland } \\
\hline & \multirow{2}{*}{$\mathrm{L}$} & \multicolumn{2}{|c|}{ Wi } & \multirow{2}{*}{$\mathrm{T}$} & \multirow{2}{*}{ We } & \multirow{2}{*}{$\mathrm{L}$} & \multicolumn{2}{|c|}{$\mathrm{Wi}$} & \multirow{2}{*}{$\mathrm{T}$} & \multirow{2}{*}{ We } \\
\hline & & cranial & caudal & & & & cranial & caudal & & \\
\hline Female & $24.50 \mathrm{a}$ & $13.83 \mathrm{a}$ & $8.00 \mathrm{a}$ & $7.00 \mathrm{a}$ & $1.38 \mathrm{a}$ & $27.83 a$ & $13.67 \mathrm{a}$ & $7.50 \mathrm{a}$ & $6.67 \mathrm{a}$ & $1.54 \mathrm{a}$ \\
\hline Male & $20.17 \mathrm{a}$ & $14.00 \mathrm{a}$ & $5.50 \mathrm{~b}$ & $5.17 \mathrm{a}$ & $0.72 \mathrm{a}$ & $23.00 \mathrm{a}$ & $11.17 \mathrm{~b}$ & $6.83 \mathrm{a}$ & $5.50 \mathrm{a}$ & $0.91 \mathrm{a}$ \\
\hline
\end{tabular}

L: length (mm); Wi: width (mm); T: thickness (mm); We: weight of the gland (g). *Identification according to the dental arch. Averages followed by the same letter in the column do not differ from each other by the Wilcoxon-Mann-Whitney test (considering $\alpha=5 \%$ ). 
Table 7. Spearman's correlation results for the influence of the animal weight on the length, width of the cranial and caudal poles, thickness, and weight of the right and left adrenal glands of mongrel dogs (males and females) necropsied in the Setor de Patologia Animal of the Hospital Veterinário of the Universidade Federal do Espírito Santo (HOVET-UFES).

\begin{tabular}{|c|c|c|c|c|c|c|c|c|c|c|c|}
\hline \multirow{3}{*}{ Group } & \multirow{3}{*}{$\begin{array}{c}\text { Weight } \\
(\bar{x})\end{array}$} & \multicolumn{5}{|c|}{ Right adrenal gland } & \multicolumn{5}{|c|}{ Left adrenal gland } \\
\hline & & \multirow{2}{*}{$\mathrm{L}$} & \multicolumn{2}{|c|}{ Wi } & \multirow{2}{*}{$\mathrm{T}$} & \multirow{2}{*}{ We } & \multirow{2}{*}{$\mathrm{L}$} & \multicolumn{2}{|c|}{ Wi } & \multirow{2}{*}{$\mathrm{T}$} & \multirow{2}{*}{ We } \\
\hline & & & cranial & caudal & & & & cranial & caudal & & \\
\hline Young & 9 & $0.63^{*}$ & 0.53 & 0.43 & 0.50 & $0.73^{*}$ & 0.51 & 0.52 & 0.41 & 0.32 & $0.84^{*}$ \\
\hline Adult & 13.62 & $0.69^{*}$ & 0.35 & $0.76^{*}$ & 0.41 & $0.82 *$ & $0.81^{*}$ & 0.47 & 0.56 & 0.52 & $0.61 *$ \\
\hline Elderly & 18.33 & $0.91 *$ & $0.75^{*}$ & $0.67 *$ & $0.78^{*}$ & $0.93^{*}$ & $0.83^{*}$ & $0.72 *$ & 0.28 & $0.64 *$ & $0.86^{*}$ \\
\hline
\end{tabular}

L: length (mm); Wi: width (mm); T: thickness (mm); We: weight of the gland (g). *Identification according to the dental arch. *Significant at the level of 5\%.

Table 8. Comparison between averages of mongrel dogs of both sexes necropsied in the Setor de Patologia Animal of the Hospital Veterinário of the Universidade Federal do Espírito Santo (HOVET-UFES) in relation to the age of the animal.

\begin{tabular}{|c|c|c|c|c|c|c|c|c|c|c|}
\hline \multirow{3}{*}{ Group } & \multicolumn{5}{|c|}{ Right adrenal gland } & \multicolumn{5}{|c|}{ Left adrenal gland } \\
\hline & \multirow{2}{*}{$\mathrm{L}$} & \multicolumn{2}{|c|}{$\mathrm{Wi}$} & \multirow{2}{*}{$\mathrm{T}$} & \multirow{2}{*}{ We } & \multirow{2}{*}{$\mathrm{L}$} & \multicolumn{2}{|c|}{$\mathrm{Wi}$} & \multirow{2}{*}{$\mathrm{T}$} & \multirow{2}{*}{ We } \\
\hline & & cranial & caudal & & & & cranial & caudal & & \\
\hline Young & $19.92 a$ & $12.08 \mathrm{a}$ & $5.67 \mathrm{a}$ & $4.91 \mathrm{a}$ & $0.61 \mathrm{a}$ & $21.67 \mathrm{a}$ & $11.92 \mathrm{a}$ & $5.92 \mathrm{a}$ & $4.58 \mathrm{a}$ & $0.75 \mathrm{a}$ \\
\hline Adult & $21.92 \mathrm{a}$ & $12.92 \mathrm{a}$ & $8.09 \mathrm{~b}$ & $5.25 \mathrm{a}$ & $0.84 \mathrm{a}$ & $23.83 \mathrm{a}$ & $13.00 \mathrm{a}$ & $7.25 \mathrm{a}$ & $5.35 \mathrm{ab}$ & $0.89 \mathrm{a}$ \\
\hline Elderly & $22.33 a$ & $13.92 \mathrm{a}$ & $6.75 \mathrm{ab}$ & $6.08 \mathrm{a}$ & $1.05 \mathrm{a}$ & $25.42 \mathrm{a}$ & $12.42 \mathrm{a}$ & $7.17 \mathrm{a}$ & $6.08 \mathrm{~b}$ & $1.22 \mathrm{a}$ \\
\hline
\end{tabular}

L: length (mm); Wi: width (mm); T: thickness (mm); We: weight of the gland (g). *Identification according to the dental arch. Averages followed by the same letter in the column do not differ from each other by the Kruskal-Wallis test $(\alpha=5 \%)$.

Table 9. Comparison between the mean length, width, thickness, and weight of the right and left adrenal glands in female mongrel dogs of different ages necropsied in the Setor de Patologia Animal of the Hospital Veterinário of the Universidade Federal do Espírito Santo (HOVET-UFES).

\begin{tabular}{|c|c|c|c|c|c|c|c|c|c|c|}
\hline \multirow{3}{*}{ Group } & \multicolumn{5}{|c|}{ Right adrenal gland } & \multicolumn{5}{|c|}{ Left adrenal gland } \\
\hline & \multirow{2}{*}{$\mathrm{L}$} & \multicolumn{2}{|c|}{$\mathrm{Wi}$} & \multirow{2}{*}{$\mathrm{T}$} & \multirow{2}{*}{ We } & \multirow{2}{*}{$\mathrm{L}$} & \multicolumn{2}{|c|}{ Wi } & \multirow{2}{*}{$\mathrm{T}$} & \multirow{2}{*}{ We } \\
\hline & & cranial & caudal & & & & cranial & caudal & & \\
\hline Young & $22.17 \mathrm{a}$ & $12.67 \mathrm{a}$ & $5.83 \mathrm{a}$ & $4.75 \mathrm{a}$ & $0.65 \mathrm{a}$ & $24.00 \mathrm{a}$ & $12.00 \mathrm{a}$ & $6.17 \mathrm{a}$ & $4.67 \mathrm{a}$ & $0.70 \mathrm{a}$ \\
\hline Adult & $20.83 a$ & $14.17 \mathrm{a}$ & $8.33 \mathrm{a}$ & $5.00 \mathrm{ab}$ & $0.82 \mathrm{a}$ & $23.17 \mathrm{a}$ & $12.00 \mathrm{a}$ & $7.00 \mathrm{a}$ & $5.50 \mathrm{a}$ & $0.90 \mathrm{a}$ \\
\hline Elderly & $24.50 \mathrm{a}$ & $13.83 \mathrm{a}$ & $8.00 \mathrm{a}$ & $7.00 \mathrm{~b}$ & $1.38 \mathrm{a}$ & $27.83 \mathrm{a}$ & $13.67 \mathrm{a}$ & $7.50 \mathrm{a}$ & $6.67 \mathrm{a}$ & $1.54 \mathrm{a}$ \\
\hline
\end{tabular}

L: length (mm); Wi: width (mm); T: thickness (mm); We: weight of the gland (g). *Identification according to the dental arch. Averages followed by the same letter in the column do not differ by the Kruskal-Wallis test $(\alpha=5 \%)$.

Table 10. Comparison between the average length, width, thickness, and weight of the right and left adrenal glands of male mongrel dogs of different ages necropsied in the Setor de Patologia Animal of the Hospital Veterinário of the Universidade Federal do Espírito Santo (HOVET-UFES).

\begin{tabular}{|c|c|c|c|c|c|c|c|c|c|c|}
\hline \multirow{3}{*}{ Group } & \multicolumn{5}{|c|}{ Right adrenal gland } & \multicolumn{5}{|c|}{ Left adrenal gland } \\
\hline & \multirow{2}{*}{$\mathrm{L}$} & \multicolumn{2}{|c|}{$\mathrm{Wi}$} & \multirow{2}{*}{$\mathrm{T}$} & \multirow{2}{*}{ We } & \multirow{2}{*}{$\mathrm{L}$} & \multicolumn{2}{|c|}{$\mathrm{Wi}$} & \multirow{2}{*}{$\mathrm{T}$} & \multirow{2}{*}{ We } \\
\hline & & cranial & caudal & & & & cranial & caudal & & \\
\hline Young & $17.67 \mathrm{a}$ & $11.50 \mathrm{a}$ & $5.50 \mathrm{a}$ & $4.83 \mathrm{a}$ & $0.56 \mathrm{a}$ & $19.33 \mathrm{a}$ & $11.83 \mathrm{a}$ & $5.67 \mathrm{a}$ & $4.50 \mathrm{a}$ & $0.80 \mathrm{a}$ \\
\hline Adult & $23.00 \mathrm{a}$ & $11.67 \mathrm{a}$ & $7.83 \mathrm{a}$ & $5.50 \mathrm{a}$ & $0.86 \mathrm{a}$ & $24.50 \mathrm{a}$ & $14.00 \mathrm{a}$ & $7.50 \mathrm{a}$ & $5.20 \mathrm{a}$ & $0.89 \mathrm{a}$ \\
\hline Elderly & $20.17 \mathrm{a}$ & $14.00 \mathrm{a}$ & $5.50 \mathrm{~b}$ & $5.17 \mathrm{a}$ & $0.72 \mathrm{a}$ & $23.00 \mathrm{a}$ & $11.17 \mathrm{~b}$ & $6.83 a$ & $5.50 \mathrm{a}$ & $0.91 \mathrm{a}$ \\
\hline
\end{tabular}

L: length (mm); Wi: width (mm); T: thickness (mm); We: weight of the gland (g). *Identification according to the dental arch. Averages followed by the same letter in the column do not differ by the Kruskal-Wallis test $(\alpha=5 \%)$.

\section{DISCUSSION}

Studies on the size of the adrenal gland in dogs using macroscopic biometrics are scarce and the current study presents results regarding mixed-breed (male and female) dogs of different ages, which showed variation in size and weight, which could also influence the size of the adrenal gland. Thus, we discuss the found results with ultrasound examination reports.
Several authors have reported the measurement of the adrenal glands by means of ultrasound examinations in healthy animals or even in the diagnosis of diseases affecting the adrenal glands [6,10,12,15,25]. On ultrasound examinations, the right adrenal gland can measure from 10 to $39.3 \mathrm{~mm}$ in length, 3.1 to 12 $\mathrm{mm}$ in width at its caudal pole, and 2.0 to $5.0 \mathrm{~mm}$ in thickness, whereas the left adrenal gland can measure 


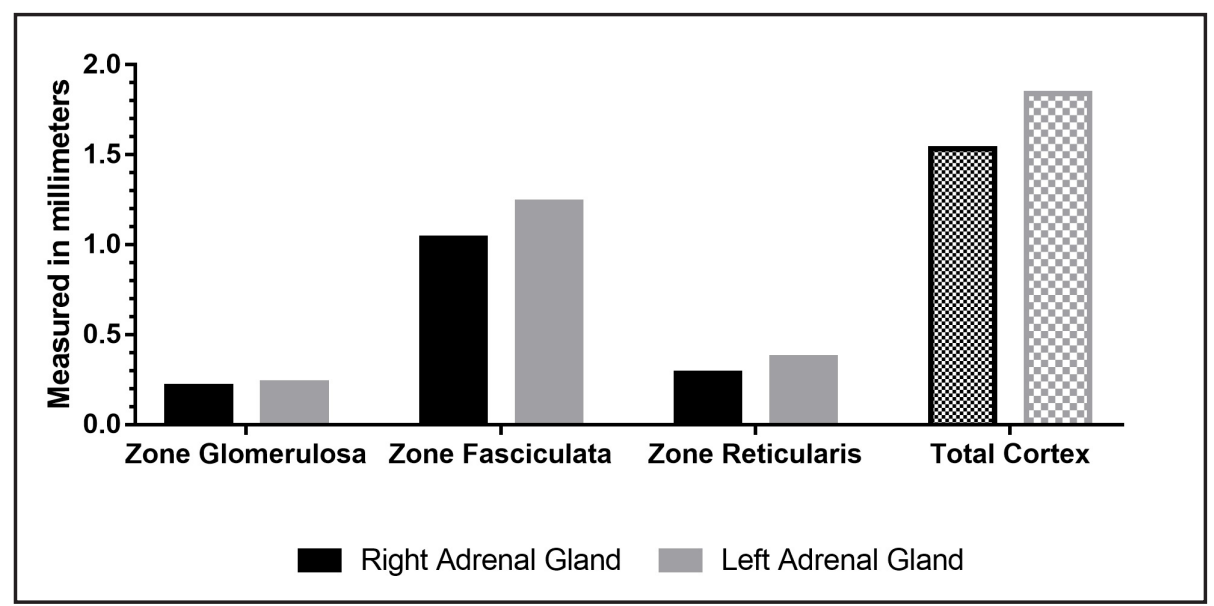

Figure 1. Values $(\mathrm{mm})$ of the right and left adrenal glands of mongrel dogs of different ages and both sexes. The zona fasciculata occupies the highest proportion of the adrenal cortex in both the right $(P<0.0001)$ and left $(P<0.0001)$ adrenal glands. There was no significant difference between the right and left adrenal glands as measured by the zona glomerulosa $(P=0.3270)$, zona fasciculata $(P=0.7213)$, zona reticularis $(P$ $=0.2845)$ and total cortex $(P=0.2411)$.

from 10.7 to $50.2 \mathrm{~mm}$ in length, 1.9 to $12.4 \mathrm{~mm}$ in width at the caudal pole, and 3.0 to $5.0 \mathrm{~mm}$ in thickness [4]. However, an ultrasound study showed that the right adrenal cortex of normal dogs had a length of 12.4-22.6 mm and thickness of 3.1-6.0 mm, and the left adrenal cortex had a length of 13.2-26.3 $\mathrm{mm}$ and thickness of 3.0-5.2 $\mathrm{mm}$ [15]. On ultrasound examinations, the length of the adrenal glands can range from 15 to $30 \mathrm{~mm}$, the width can range from 4.0 to $20 \mathrm{~mm}$, and thickness can range from 3.5 to $11 \mathrm{~mm}$ [3]. One study reported that the average thickness of the adrenal gland of 10 healthy dogs was $6.0 \mathrm{~mm}$ in both the right and left gland [12]. Thus, it can be observed that a variation of measurements can be found by ultrasound examination, the need to find homogeneous measures that serve as a diagnostic parameter, especially for dogs with no defined breed.

An ultrasonographic study comparing the macroscopic size of the adrenal glands of dogs of different breeds with a mean body weight of $17.5 \mathrm{~kg}$ (1.3-52 $\mathrm{kg}$ ) and mean age of 10 years (1-17 years) found the following averages for the macroscopic evaluations of the right adrenal glands: area, $230.8 \mathrm{~mm}^{2}$; length, 25.49 $\mathrm{mm}$; cranial thickness, $10.38 \mathrm{~mm}$; mean thickness, 7.74 $\mathrm{mm}$; and flow thickness, $6.17 \mathrm{~mm}$. In the left adrenal, the authors found the following results: area, 240.9 $\mathrm{mm}^{2}$; length, $25.41 \mathrm{~mm}$; cranial thickness, $9.36 \mathrm{~mm}$; mean thickness, $5.85 \mathrm{~mm}$; and flow thickness, 7.43 $\mathrm{mm}$. In the ultrasound evaluations, the authors found the following averages: right adrenal - area, $231.7 \mathrm{~mm}^{2}$; length, $27.05 \mathrm{~mm}$; cranial thickness, $11.47 \mathrm{~mm}$; mean thickness, $6.53 \mathrm{~mm}$; and flow thickness, $5.96 \mathrm{~mm}$; left adrenal - area, $164.3 \mathrm{~mm}^{2}$; length, $26.36 \mathrm{~mm}$; cranial thickness, $6.95 \mathrm{~mm}$; mean thickness, $4.69 \mathrm{~mm}$; and flow thickness, $7.17 \mathrm{~mm}$. The results found by the authors demonstrated that the accuracy of the ultrasound measurements ranged from $0 \%$ to $25.21 \%$ (relative error); the smallest error was found for the caudal pole thickness, length, and area of the right adrenal [20]. These results demonstrate the importance of studies that perform the macroscopic analysis of such glands, as described in the present study.

When comparing the length, width of the cranial and caudal poles, thickness, and weight of the right and left adrenals analyzed in the study, there was no significant difference for young, adult, and elderly mongrel dogs, except for the caudal pole widths of the right adrenal and adrenal cranial poles of the elderly dogs, who presented a significant difference. In an ultrasound study of the adrenal glands of adult dogs, observed a significant difference only in the cranial pole thickness and caudal pole width, with differences observed for dogs weighing over $10 \mathrm{~kg}$ [23]. Thus, there was a difference in the age at which the width of the caudal pole showed a statistical difference between the studies. Regarding the adrenal gland weight, adrenals of medium-sized male dogs had a weight of 1.14 $\mathrm{g}$ and no significant difference between weight of the right and left adrenal gland was found [1], while in the present study, the weight found was $0.865 \mathrm{~g}$ and 
significant difference between weight of the right and left adrenal gland also was not found.

Adrenal size was higher in young individuals than in adults [8]. However, this characteristic was not observed in the present study. There is a correlation between the age of the studied animals and the length of the left adrenal gland [6], which was not detected in the present experiment. Different from the findings of the present study, was observed a significant difference in the adrenal weight, length, and thickness between the age groups, in which young dogs presented lighter and smaller glands than did the adult and elderly dogs (young < adult < elderly) [22]. The differences found by these authors may have occurred because the number of animals with some type of disease was high. It is important to study the measurements of the adrenal glands of elderly animals, because animals of this age group are the most susceptible to presenting with histopathological lesions in this organ [21].

In the present study, the correlation between the right adrenal gland length and animal weight was significant for all groups: $r=0.63$ for young, $r$ $=0.69$ for adult, and $r=0.91$ for elderly dogs. In the left adrenal, the correlation was significant only in adult $(r=0.81)$ and elderly $(r=0.83)$ dogs. A study that evaluated the adrenal gland measurement and its correlation with the weight of the animals by ultrasonography found a strong linear association between the left adrenal length $(r=0.71)$ and the weight of the animals and the similar significance between the right adrenal length and the animals weight $(r=0.69)$ [6]. However, when used ultrasonographic examination to perform measurements on the adrenal glands of adult dogs found a moderate correlation between the gland length and animal weight: for dogs weighing less than $10 \mathrm{~kg}(r=0.6)$, dogs weighing $10-30 \mathrm{~kg}(r=0.59)$, and dogs weighing more than $30 \mathrm{~kg}(r=0.69)$ [23]. The discrepancy between strong and moderate correlations in studies may occur due to the number of animals and even the accuracy of the examination. Thus, studies that measure the organ directly, such as the one performed here, may present a greater accuracy in the results.

The adrenal gland measurement results of adult dogs in this study, with a mean weight of 13.62 $\mathrm{kg}(6.6-24.5 \mathrm{~kg})$, differ from those found for length $(27 \mathrm{~mm})$ and weight $(2.55 \mathrm{~g})$ reported in another study [9], who carried out the experiment with adult German Shepherd dogs with body weights ranging from 30-40 $\mathrm{kg}$. However, the results found by the aforementioned author for width $(14 \mathrm{~mm})$ and thickness $(5 \mathrm{~mm})$ of the adrenals were close to those found in this study. Using ultrasonography to measure the adrenal glands of adult dogs with an average weight of $8.5 \mathrm{~kg}(2-15 \mathrm{~kg})$, found values of length $(15.8 \mathrm{~mm})$ and widths of the cranial pole $(4.15 \mathrm{~mm})$ and caudal pole $(4.7 \mathrm{~mm})$ [10], smaller than those found in the present study. According to the results presented here, there is a positive correlation in young, adult, and elderly animals for the animal weight and adrenal length and weight, with the exception of the left adrenal length in young animals. Two studies also found that dogs with a higher weight had longer and heavier adrenal glands, while smaller dogs had shorter adrenal glands $[9,10]$.

An ultrasound evaluation in dogs with several adrenal gland changes, and found a positive correlation between the body weight and adrenal length but did not observe a correlation between the body weight and gland thickness [24]. However, an ultrasonographic comparative analysis of healthy dogs with adrenal alterations and found no correlation between the age of the animals and the gland length, and also no correlation between the body weight and the adrenal thickness and length [18].

In this study, when comparing the right and left adrenal measurements of females and males of different ages, a statistical difference was observed for the right adrenal thickness; elderly females presented higher values. For males, difference was observed between the width of the right caudal pole and the width of the left cranial pole, in which elderly males presented lower values. In a study no difference between the measurements of the adrenal glands using ultrasonography was found, considering the sex of the animals [6].

There was no difference in the measurements of the different zones of the right and left adrenal cortices. The most prominent area was the zona fasciculata at $66.9 \%$ and $63.96 \%$, followed by the zona reticularis at $18.5 \%$ and $22.84 \%$ and the zona glomerulosa at $14.6 \%$ and $13.2 \%$, for the right and left adrenal glands, respectively. Thus, the greatest proportion being the zona fasciculata is in accordance to other reports of $[5,7,13]$, although these authors reported that the proportions of this zona in the cortex were $80 \%$ and $60 \%$, respectively. The results found here differ from another studies that indicate that the zona glomerulosa 
(15\%-25\%) are more bulky than the zona reticularis $(5 \%-15 \%)[5,13,14]$. However, these authors did not mention the breed, weight, or sex of the animals involved in the determination of the proportions of each zone in the adrenal cortex.

The animals in this study had no clinical signs compatible with any pathological process related to the adrenal glands, especially in the zona reticularis of the cortical layer, which resulted in data that diverged more significantly than the other areas that were mentioned $[5,13,14]$.

The microscopic biometry of the cortical layer and its zones is made from the histological evaluation of the adrenal glands, thus requiring histological processing in which tissue dehydration occurs; this reduces the actual size of the organ. The various steps of this procedure can distort the tissues, providing an image that may differ from that presented when alive [16]. One cause of distortion is the retraction produced by the fixing solution, ethanol, and the heat of the paraffin used for inclusion, so these factors must be considered during microscopic measurement for a better understanding of the histological picture.

\section{CONCLUSIONS}

Based on the results obtained in this study, there was a clear variation in the size of the adrenal glands of different groups of mixed-breed dogs, and the left adrenal gland presented a greater mean length and weight than the right gland. The sex of the animals did not influence the size of the glands of young and adult dogs, but in elderly dogs, the females had a mean width greater than that of the males.

The weight of the animals presented a positive correlation in relation to the length and weight of the right and left adrenal glands in all studied groups, except for the left adrenal length in young dogs. Age did not influence the length and weight of the glands; however, some differences were observed in the elderly group in the thickness and width, when compared to the other groups.

The proportions of the right and left adrenal cortices show that the zona fasciculata composes the highest percentage, followed by the zona reticularis and zona glomerulosa.

Although significant morphological variations have been found in the adrenal glands of dogs of the present study, it is believed that further research should be directed towards the establishment of adrenal gland biometry patterns in dogs.

\section{MANUFACTURER \\ ${ }^{1}$ AnMo Electronics Corporation. Taiwan, China.}

Ethical approval. This study was carried out according to the recommendations of Brazilian College of Animal Experimentation (COBEA-SBCAL) and Guide for the Care and Use of Laboratory Animals - National Research Council-National Academies.

Declaration of interest. The authors report no conflicts of interest. The authors alone are responsible for the content and writing of paper.

\section{REFERENCES}

1 Baker D.D. 1936. Studies on the suprarenal glands of dogs. I. Comparasion of the weigths of suprarenal glands of mature and immature male and female dogs. American Journal of Anatomy. 60: 231-252.

2 Barthez P.Y., Nyland T.G. \& Feldman E.C. 1995. Ultrasonographic evaluation of the adrenal glands in dogs. Journal of the American Veterinary Medical Association. 207: 1180-1183.

3 Burk R.L. \& Feeney D.A. 2003. Small Animal Radiology and Ultrasonography. A diagnostic Atlas and Text. 3rd edn. Saint Louis: Saunders, 784 p.

4 Carvalho C.F. 2014. Ultrasonografia em Pequenos Animais. 2.ed. São Paulo: Roca, 468p.

5 De Marco V. 2014. Hiperadrenocorticismo canino. In: Jericó M.M., Andrade Neto J.P.D. \& Kogika M.M. (Eds). Tratado de Medicina Interna de Cães e Gatos. 2 vol. São Paulo: Roca, pp.1691-1703.

6 Douglass J.P., Berry C.R. \& James S. 1997. Ultrasonographic adrenal gland measurements in dogs without evidence of adrenal disease. Veterinary Radiology \& Ultrasound. 38: 124-130.

7 Drazner F.H. 1987. Small Animal Endocrinology. New York: Churchill Livingstone, 508p.

8 Dyce K.M., Sack W.O. \& Wensing C.J.G. 2010. Tratado de Anatomia Veterinária. 4.ed. Rio de Janeiro: Elsevier, 856p.

9 Faria M.D. 2007. Dimensões e massas dos órgãos internos de cães Pastores Alemães (Canis familiaris Linnaeus, 1758). 250f. São Paulo, SP. Tese (Doutorado em Ciências) - Programa de Pós-Graduação em Anatomia dos Animais Domésticos e Silvestres, Universidade de São Paulo. 
10 Fernandez S., Feliciano M.A.R., Crivellenti S.B., Crivellenti L.Z., Simões A.P.R., Maronezi M.C., Uscategui R.R., Capela C.R., Gilor C., Santana A.E. \& Vicente W.R.R. 2016. B-mode and Doppler ultrasonography of adrenal glands of healthy dogs. Arquivo Brasileiro de Medicina Veterinária e Zootecnia. 68: 907-912.

11 Gartner L.P. \& Hiatt J.L. 2014. Atlas Colorido de Histologia. 6.ed. Rio de Janeiro: Guanabara Koogan, 494p.

12 Grooters A.M., Biller D.S., Theisen S.K. \& Miyabayashi T. 1996. Ultrasonographic characteristics of the adrenal glands in dogs with pituitary-dependent hyperadrenocorticism: comparison with normal dogs. Journal of Veterinary Internal Medicine. 10: 110-115.

13 Herrtage M.E. 1990. The adrenal glands In: Hutchison M. (Ed). Manual of Small Animal Endocrinology. Cheltenham: British Small Animal Veterinary Associaton, pp.22-23, 73-78, 96-101.

14 Herrtage M.E. \& Ramsey I.K. 2015. Hiperadrenocorticismo em Cães. In: Mooney C.T., Peterson M.E. \& Fagliari J.J. (Eds). Manual de Endocrinologia em Cães e Gatos. 4.ed. São Paulo: Roca, pp.254-289.

15 Hoerauf A. \& Reusch C. 1999. Ultrasonographic evaluation of the adrenal glands in six dogs with hypoadrenocorticism. Journal of the American Animal Hospital Association. 35: 214-218.

16 Junqueira L.C., Carneiro J. \& Abrahamsohn P. 2017. Histologia Básica. 13.ed. Rio de Janeiro: Guanabara Koogan, $568 \mathrm{p}$.

17 König H.E. \& Liebich H. 2016. Anatomia dos Animais Domésticos. Texto e Atlas Colorido. 6.ed. Porto Alegre: Artmed. $824 \mathrm{p}$.

18 Lobetti R., Lindquist E., Frank J., Marek D.C.K. \& Timon T. 2016. Retrospective study of adrenal gland ultrasonography in dogs with normal and abnormal Acth stimulation test. Journal of Veterinary Clinical Practice and Pet Care. 1: 1-6.

19 Mogicato G., Layssol-Lamour C., Conchou F., Diquelou A., Raharison F., Sautet J. \& Concordet D. 2011. Ultrasonographic evaluation of the adrenal glands in healthy dogs: repeatability, reproducibility, observer-dependent variability, and the effect of bodyweight, age and sex. Veterinary Record. 168: 130.

20 Pagani E., Tarducci A., Borrelli A., Iotti B., Tursi M. \& Zanatta R. 2017. Accuracy of ultrasonographic measurements of adrenal glands in dogs: comparison with necroscopic findings. Anatomia, Histologia, Embryologia. 46: 187-194.

21 Pagani E., Tursi M., Lorenzi C., Tarducci A., Bruno B., Borgogno Mondino E.C. \& Zanatta R. 2016. Ultrasonographic features of adrenal gland lesions in dogs can aid in diagnosis. BMC Veterinary Research. 12: 267.

22 Salvagni F., de Siqueira A., Maria A.C. \& Maiorka P. 2017. Morphometric and histopathological findings in the adrenal glands of dogs with chronic diseases. Brazilian Journal of the Veterinary Pathology. 10: 69-78.

23 Soulsby S.N., Holland M., Hudson J.A. \& Behrend E.N. 2015. Ultrasonographic evaluation of adrenal gland size compared to body weight in normal dogs. Veterinary Radiology \& Ultrasound. 56: 317-326.

24 Wenger M., Mueller C., Kook P.H. \& Reusch C.E. 2010. Ultrasonographic evaluation of adrenal glands in dogs with primary hypoadrenocorticism or mimicking diseases. Veterinary Record. 167: 207-210.

25 Yeh H.C. 1980. Sonography of the adrenal glands: normal glands and small masses. American Journal of Roentgenology. 135: 1167-1177. 